\title{
Neurologic and neuroimaging findings in patients with COVID-19
}

\author{
A retrospective multicenter study
}

Stéphane Kremer, MD, PhD, * François Lersy, MD, * Mathieu Anheim, MD, PhD, * Hamid Merdji, MD, Maleka Schenck, MD, Hélène Oesterlé, MD, Federico Bolognini, MD, Julien Messie, MD, Antoine Khalil, MD, Augustin Gaudemer, MD, Sophie Carré, MD, Manel Alleg, MD, Claire Lecocq, MD, Emmanuelle Schmitt, MD, René Anxionnat, MD, PhD, François Zhu, MD, Lavinia Jager, MD, Patrick Nesser, MD, Yannick Talla Mba, MD, Ghazi Hmeydia, MD, Joseph Benzakoun, MD, Catherine Oppenheim, MD, PhD,

Jean-Christophe Ferré, MD, PhD, Adel Maamar, MD, Béatrice Carsin-Nicol, MD, Pierre-Olivier Comby, MD,

Frédéric Ricolfi, MD, PhD, Pierre Thouant, MD, Claire Boutet, MD, PhD, Xavier Fabre, MD,

Géraud Forestier, MD, Isaure de Beaurepaire, MD, Grégoire Bornet, MD, Hubert Desal, MD, PhD,

Grégoire Boulouis, MD, Jérome Berge, MD, Apolline Kazémi, MD, Nadya Pyatigorskaya, MD, PhD,

Augustin Lecler, MD, PhD, Suzana Saleme, MD, Myriam Edjlali-Goujon, MD, PhD, Basile Kerleroux, MD,

Jean-Marc Constans, MD, PhD, Pierre-Emmanuel Zorn, PhD, Muriel Mathieu, PhD, Seyyid Baloglu, MD,

François-Daniel Ardellier, MD, Thibault Willaume, MD, Jean-Christophe Brisset, PhD, Sophie Caillard, MD, PhD,

Olivier Collange, MD, PhD, Paul Michel Mertes, MD, PhD, Francis Schneider, MD, PhD,

Samira Fafi-Kremer, PharmD, PhD, Mickael Ohana, MD, PhD, Ferhat Meziani, MD, PhD,

Nicolas Meyer, MD, PhD, Julie Helms, MD, PhD, and François Cotton, MD, PhD

Neurology ${ }^{\circledR}$ 2020;95:e1868-e1882. doi:10.1212/WNL.0000000000010112

\section{Abstract}

\section{Objective}

To describe neuroimaging findings and to report the epidemiologic and clinical characteristics of patients with coronavirus disease 2019 (COVID-19) with neurologic manifestations.

\section{Methods}

In this retrospective multicenter study (11 hospitals), we included 64 patients with confirmed COVID-19 with neurologic manifestations who underwent a brain MRI.

\section{Results}

The cohort included 43 men (67\%) and 21 women (33\%); their median age was 66 (range 20-92) years. Thirty-six (56\%) brain MRIs were considered abnormal, possibly related to severe acute respiratory syndrome coronavirus. Ischemic strokes (27\%), leptomeningeal

\author{
Correspondence \\ Dr. Kremer \\ stephane.kremer@ \\ chru-strasbourg.fr
}

\section{MORE ONLINE}

\section{COVID-19 Resources}

For the latest articles, invited commentaries, and blogs from physicians around the world NPub.org/COVID19

\section{- CME Course}

NPub.org/cmelist

\footnotetext{
*These authors contributed equally to this work.

From the Hôpitaux Universitaires de Strasbourg (S.K., F.L., S.B., F.-D.A., T.W.), Service d'imagerie 2, Hôpital de Hautepierre; Engineering Science, Computer Science and Imaging Laboratory (S.K., N.M.), UMR 7357, University of Strasbourg-CNRS; Service de Neurologie (M. Anheim), Hôpitaux Universitaires de Strasbourg; Institut de Génétique et de Biologie Moléculaire et Cellulaire (M. Anheim), INSERM-U964/CNRS-UMR7104/Université de Strasbourg, Illkirch; Fédération de Médecine Translationnelle de Strasbourg (M. Anheim), Université de Strasbourg; Hôpitaux universitaires de Strasbourg (H.M., F.M., J.H.), Service de Médecine Intensive Réanimation, Nouvel Hôpital Civil; INSERM (French National Institute of Health and Medical Research) (H.M., F.M.), UMR 1260, Regenerative Nanomedicine, Fédération de Médecine Translationnelle de Strasbourg; Médecine Intensive-Réanimation (M.S., F.S.), Hôpital de Hautepierre, Hôpitaux Universitaires de Strasbourg; Service de Neuroradiologie (H.O., F.B., J.M.), Hôpitaux Civils de Colmar; Service d'Imagerie (A. Khalil, A.G.), Unité de Neuroradiologie, Assistance Publique-Hôpitaux de Paris, Hôpital Bichat Claude Bernard; Université Paris Diderot (A. Khalil), Paris; Service de Neurologie (S. Carré, C.L.), Centre Hospitalier de Haguenau; Service de Radiologie (M. Alleg), Centre Hospitalier de Haguenau; Service de Neuroradiologie, (E.S., R.A., F.Z.) Hôpital Central, CHU de Nancy; CHIC Unisanté (L.J., P.N., Y.T.M.), Hôpital Marie Madeleine, Forbach; Neuroimaging Department (G.H., J. Benzakoun, C.O., G. Boulouis, M.E.-G., B.K.), GHU Paris Psychiatrie et Neurosciences, Hôpital Sainte-Anne, Université de Paris, INSERM U1266, F-75014; CHU Rennes (J.-C.F., B.C.-N.), Department of Neuroradiology; CHU Rennes (A.M.), Medical Intensive Care Unit; Department of Neuroradiology (P.-O.C., F.R., P.T.), University Hospital of Dijon, Hôpital François Mitterrand; Service de Radiologie (C.B.), CHU de Saint-Etienne; Service de Réanimation (X.F.), CH de Roanne; Service de Neuroradiologie (G.F., S.S.), CHU de Limoges; Radiology Department (I.d.B., G. Bornet), Hôpital Privé d'Antony; Department of Diagnostic and Interventional Neuroradiology (H.D.), University Hospital, Nantes; Neuroradiology Department (I. Berge), CHU de Bordeaux; Service de Neuroradiologie (A. Kazémi), CHU de Lille; Assistance Publique Hôpitaux de Paris (N.P.), Service de Neuroradiologie, Hôpital Pitié-Salpêtrière; Sorbonne Université (N.P.), Univ Paris 06, UMR S 1127, CNRS UMR 7225, ICM, F-75013; Service de Neuroradiologie Diagnostique (A.L.), Foundation A. Rothschild Hospital, Paris; EA CHIMERE 7516 (J.-M.C.), Université de Picardie Jules Verne; Service de NeuroRadiologie, pôle Imagerie Médicale, Centre Hospitalo-Universitaire d'Amiens; Hôpitaux Universitaires de Strasbourg (P.-E.Z., M.M.), UCIEC, Pôle d'Imagerie, Strasbourg; Observatoire Français de la Sclérose en Plaques (J.-C.B.), Lyon; Nephrology and Transplantation Department (S. Caillard), Hôpitaux Universitaires de Strasbourg; Inserm UMR S1109 (S. Caillard), LabEx Transplantex, Fédération de Médecine Translationnelle de Strasbourg, Université de Strasbourg; Hôpitaux Universitaires de Strasbourg (O.C., P.M.M.), Service d'Anesthésie-Réanimation, Nouvel Hôpital Civil; Hôpitaux Universitaires de Strasbourg (S.F.-K.), Laboratoire de Virologie Médicale; Radiology Department (M.O.), Nouvel Hôpital Civil, Strasbourg University Hospital; CHU de Strasbourg (N.M.), Service de Santé Publique, GMRC, F-67091 Strasbourg; Immuno-Rhumatologie Moléculaire (S.F.-K., J.H.), INSERM UMR_S1109, LabEx TRANSPLANTEX, Centre de Recherche d'Immunologie et d'Hématologie, Faculté de Médecine, Fédération Hospitalo-Universitaire OMICARE, Fédération de Médecine Translationnelle de Strasbourg, Université de Strasbourg; MRI Center (F.C.), Centre Hospitalier Lyon Sud, Hospices Civils de Lyon; and Université Lyon 1 (F.C.), CREATIS-LRMN, CNRS/UMR/5220-INSERM U630, Villeurbanne, France.
}

Go to Neurology.org/N for full disclosures. Funding information and disclosures deemed relevant by the authors, if any, are provided at the end of the article. 
enhancement (17\%), and encephalitis (13\%) were the most frequent neuroimaging findings. Confusion (53\%) was the most common neurologic manifestation, followed by impaired consciousness (39\%), presence of clinical signs of corticospinal tract involvement (31\%), agitation (31\%), and headache (16\%). The profile of patients experiencing ischemic stroke was different from that of other patients with abnormal brain imaging: the former less frequently had acute respiratory distress syndrome $(p=0.006)$ and more frequently had corticospinal tract signs $(p=0.02)$. Patients with encephalitis were younger $(p=0.007)$, whereas agitation was more frequent for patients with leptomeningeal enhancement $(p=0.009)$.

\section{Conclusions}

Patients with COVID-19 may develop a wide range of neurologic symptoms, which can be associated with severe and fatal complications such as ischemic stroke or encephalitis. In terms of meningoencephalitis involvement, even if a direct effect of the virus cannot be excluded, the pathophysiology seems to involve an immune or inflammatory process given the presence of signs of inflammation in both CSF and neuroimaging but the lack of virus in CSF.

\section{ClinicalTrials.gov identifier} NCT04368390.

In December 2019, many unexplained pneumonia cases occurred in China. ${ }^{1,2}$ In January 2020, the causative agent was identified as a novel coronavirus, which has been called severe acute respiratory syndrome coronavirus 2 (SARS-CoV-2), giving the disease the name coronavirus disease 2019 (COVID-19). Coronaviruses have neuroinvasive capacities because they are isolated in both brains and CSF of infected animals and humans. ${ }^{3-8}$ However, few neurologic complications with human coronaviruses (hCoVs) were documented in the past 2 decades.

Concerning COVID-19, 5 recent publications have presented neuroimaging presentations of patients with neurologic complications. ${ }^{9-13}$

The first studies that focused on clinical features of patients with COVID-19 $19^{1,2,11}$ showed neurologic manifestations such as headache, dizziness, confusion, hypogeusia, hyposmia, and more severe neurologic disorders, especially for patients hospitalized in intensive care units (ICUs). In a recent cohort of 214 patients, ${ }^{11}$ $24.8 \%$ of them presented CNS manifestations, and 6 cases of strokes were diagnosed. The neurologic symptoms were more common in cases of severe respiratory infection. ${ }^{11}$ It has recently been reported ${ }^{12}$ that patients referred to ICU frequently experienced encephalopathy with agitation, confusion, and corticospinal tract signs. Brain MRI revealed in some patients leptomeningeal enhancement (LME) and cerebral blood flow abnormalities.

Despite these findings, the potential brain injuries related to COVID-19 have not been well described with neuroimaging in a large cohort. Thus, our aims were to describe the neuroimaging findings in a population of COVID-19 with neurologic manifestations who underwent brain MRI, to assess the frequency of these abnormalities, and to correlate these findings with clinical features.

\section{Methods}

This retrospective national multicenter study was initiated by the French Neuroradiology Society.

\section{Patient cohort}

Patients with COVID-19 from 11 French centers, including 6 university hospitals and 5 general hospitals, were included from March 16, 2020, until April 9, 2020. The number of cases included from each center was as follows: 29 in Strasbourg, 11 in Colmar, 7 in Paris (Bichat), 5 in Haguenau, 4 in Nancy, 4 again in Paris (Sainte-Anne), 3 in Rennes, 2 in Dijon, 1 in Saint-Etienne, 1 in Forbach, and 1 in Antony.

The diagnosis of COVID-19 was based on the following criteria: possible exposure history, symptoms clinically compatible with COVID-19, and detection of SARS-CoV-2 by reverse transcriptase-PCR (RT-PCR) assays on the nasopharyngeal, throat, or lower respiratory tract swabs. Inclusion criteria were diagnosis of COVID-19 with neurologic manifestation and a brain MRI assessment. Exclusion criteria were missing data or noncontributory (lack of sequences, numerous artifacts) data regarding brain MRI.

The diagnosis of acute respiratory distress syndrome (ARDS) was based on Berlin criteria. ${ }^{14}$

Clinical and laboratory data were extracted from the patients' electronic medical records in the hospital information system.

\section{Virologic assessment}

Quantitative real-time RT-PCR tests for SARS-CoV-2 nucleic acid were performed on upper or lower respiratory tract swabs and CSF. Primer and probe sequences were targeting 2 regions on the $R d R p$ gene, which are specific to SARS-CoV-2. Assay sensitivity was $\approx 10$ copies per reaction.

\section{Brain MRI protocols}

Imaging studies were conducted on $1.5 \mathrm{~T}$ or $3 \mathrm{~T}$ MRI. The multicenter nature of the study and the various clinical presentations did not allow standardization of sequences.

The most frequently sequences performed were 3D T1-weighted spin-echo with and without contrast-enhanced imaging, diffusion-weighted imaging, gradient echo T2 or 
susceptibility-weighted imaging, $2 \mathrm{D}$ or $3 \mathrm{D}$ fluid-attenuated inversion recovery (FLAIR) postcontrast, and 3D time-offlight magnetic resonance angiography of the circle of Willis

\section{Brain MRI reading}

After anonymization, images were presented to readers with our GE Picture Archiving and Communication System (General Electric, Milwaukee, WI). Two neuroradiologists (S.K. and F.L., with 20 and 9 years of experience in neuroradiology, respectively) who were blinded to all patient data independently reviewed all brain MRIs. The final diagnosis was determined by consensus, and if consensus could not be reached, a third neuroradiologist (S.B., with 9 years of experience in neuroradiology) was questioned.

Neuroimaging abnormalities were divided into 3 groups: ischemic stroke, encephalitis, and LME. Ischemic strokes were classified into large artery infarctions, watershed cerebral infarctions, lacunar infarctions, and hypoxic-ischemic injuries. Encephalitis was ranked as limbic encephalitis, cytotoxic lesion of the corpus callosum (CLOCC), radiologic acute disseminated encephalomyelitis (ADEM), radiologic acute hemorrhagic necrotizing encephalopathy, and miscellaneous encephalitis.

Encephalitis was defined as brain parenchymal abnormal FLAIR hyperintensity involving gray matter (GM), white matter, or basal ganglia with variable enhancement localized mainly in medial temporal and inferior frontal lobes in case of limbic encephalitis. The term CLOCC has been proposed recently to describe a clinicoradiologic syndrome characterized by a transient mild encephalopathy and a reversible lesion of the corpus callosum, localized mainly to the central part of the splenium on MRI. CLOCCs are the consequence of numerous etiologies, the 2 most frequent being antiepileptic drug withdrawal and infections. They are related to a cytokine increase inducing glutamate elevation in the extracellular space, leading to a dysfunction of callosal neurons and microglia with intracellular water influx, resulting in cytotoxic edema. ${ }^{15}$

$\mathrm{ADEM}$ is an autoimmune-mediated disease occurring after viral infections and vaccinations. Multifocal demyelinating lesions involving white matter but also GM (basal ganglia) are seen with variable enhancement. Acute hemorrhagic necrotizing encephalopathy is a fulminant inflammatory demyelinating disease, which is considered the most severe form of ADEM, associated with hemorrhagic lesions.

A brain MRI without acute significative abnormalities or showing lesions unrelated to SARS-CoV-2 was considered normal.

\section{Statistical analysis}

Data were described with frequency and proportion (number, percent) for categorical variables and mean, median, and range for quantitative data. Categorical data were compared with the Fisher exact test. Quantitative data were compared with analysis of variance. Multiple correspondence analysis (MCA) was used to give a simultaneous multivariate description of clinical and radiologic characteristics of all diagnostic groups. MCA plots display results either for the subjects or for their characteristics. Those plots are to be interpreted on the basis of the proximity of the data points: 2 subjects who are close on a plot share a common pattern of symptoms, and 2 clinical symptoms that are close on a plot describe similar types of subjects. Ellipses are drawn around the mean position of each characteristic such that nonoverlapping ellipses can be considered to show a contrast between the subjects who share 1 or the other characteristic.

Computations were made with 3.5.3 through R-Studio with the readxl, and FactoMineR packages ( $R$ Foundation for Statistical Computing, Vienna, Austria). A value of $p<0.05$ was considered significant.

\section{Standard protocol approvals, registrations, and patient consents}

The study was approved by the ethics standards committee on human experimentation of Strasbourg University Hospital (CE-2020-37) and was in accordance with the 1964 Declaration of Helsinki and its later amendments. Due to the emergency in the context of COVID-19 pandemic responsible for acute respiratory and neurologic manifestations pandemic, the requirement for patients' written informed consent was waived.

The study has been registered in ClinicalTrials.gov (NCT04368390).

\section{Data availability}

We state that the data published are available and anonymized and will be shared on request by email to the corresponding author from any qualified investigator for purposes of replicating procedures and results.

\section{Results}

A total of 68 patients with COVID-19 were included in this multicenter study. Among them, 4 were excluded because their brain MRIs were considered noncontributory.

\section{Clinical characteristics}

The demographic and clinical characteristics of the 64 patients and their neurologic manifestations are summarized in tables 1 through 3. The most frequent neurologic manifestations were confusion/agitation/alteration of consciousness, corticospinal tract signs, and headache.

Complementary data concerning patients with COVID-19 with acute ischemic stroke are given in table 2 , including risk factors, clinical presentation, echocardiography and ECG results, neuroimaging description, and $\mathrm{D}$-dimer serum level. Further information related to patients with COVID-19 with meningoencephalitis is given in table 3 . 
Table 1 History, neurologic manifestations, and clinical characteristics of the cohort

\begin{tabular}{|c|c|c|c|c|c|}
\hline & $\begin{array}{l}\text { All patients } \\
(n=64)\end{array}$ & $\begin{array}{l}\text { Ischemic stroke } \\
(n=17)\end{array}$ & $\begin{array}{l}\text { Encephalitis } \\
(n=8)\end{array}$ & $\begin{array}{l}\text { LME } \\
(n=11)\end{array}$ & $p$ Value \\
\hline Sex, n (\%) & & & & & 0.28 \\
\hline Men & $43(67)$ & $11(65)$ & $7(88)$ & $5(46)$ & \\
\hline Women & $21(33)$ & $6(35)$ & $1(12)$ & $6(54)$ & \\
\hline Age, y & & & & & 0.007 \\
\hline Mean & 65 & 75 & 61 & 66 & \\
\hline Median & 66 & 75 & 59 & 64 & \\
\hline Range & $20-92$ & $59-92$ & $55-71$ & $51-81$ & \\
\hline History of stroke, n (\%) & $7(11)$ & $4(24)$ & 0 & $1(9)$ & 0.36 \\
\hline History of seizures, $n$ (\%) & $3(5)$ & $1(6)$ & 0 & 0 & 1 \\
\hline Another neurologic history, $\mathrm{n}(\%)$ & $9(14)$ & $2(12)$ & 0 & 0 & 0.17 \\
\hline History of autoimmune diseases, $n$ (\%) & $7(11)$ & $3(18)$ & 0 & $1(9)$ & 0.83 \\
\hline History of hematologic malignancies, $n$ (\%) & $4(6)$ & $1(6)$ & 0 & $1(9)$ & 1 \\
\hline Headaches, n (\%) & $10(16)$ & $3(18)$ & $2(25)$ & $1(9)$ & 0.85 \\
\hline Seizures, n (\%) & $1(2)$ & 0 & 0 & 0 & 1 \\
\hline Anosmia, $\mathrm{n}(\%)$ & $2(3)$ & $1(6)$ & 0 & $1(9)$ & 0.31 \\
\hline Ageusia, n (\%) & $4(6)$ & 0 & $1(13)$ & $1(9)$ & 0.45 \\
\hline Clinical signs of corticospinal tract involvement, $\mathrm{n}(\%)$ & $20(31)$ & $10(59)$ & $1(13)$ & $4(36)$ & 0.02 \\
\hline Disturbance of consciousness, $n$ (\%) & $25(39)$ & $3(18)$ & $4(50)$ & $6(55)$ & 0.15 \\
\hline Confusion, $\mathrm{n}(\%)$ & $34(53)$ & $7(41)$ & $3(38)$ & $6(55)$ & 0.34 \\
\hline Agitation, n (\%) & $20(31)$ & $1(6)$ & $3(38)$ & $7(64)$ & 0.009 \\
\hline Oxygen therapy, n (\%) & $53(83)$ & $13(76)$ & $8(100)$ & $10(91)$ & 0.52 \\
\hline ARDS, n (\%) & $33(52)$ & $3(18)$ & $6(75)$ & $8(73)$ & 0.006 \\
\hline Death, n (\%) & $7(11)$ & $2(12)$ & $2(25)$ & 0 & 0.38 \\
\hline
\end{tabular}

Abbreviations: ARDS = acute respiratory distress syndrome; $L M E=$ leptomeningeal enhancement.

\section{Neuroimaging findings}

Among the 64 MRIs included, 41 (64\%) were performed with gadolinium-based contrast agent administration. Thirty-one had a postcontrast FLAIR, and 18 had a delayed postcontrast FLAIR. The latter was achieved $\approx 10$ minutes after the injection, after the realization of conventional postcontrast FLAIR and enhanced T1-weighted imaging. Thirty-six (56\%) brain MRIs were considered abnormal, possibly related to SARS-CoV-2.

Ischemic strokes (27\%) (figure e-1, available from Dryad, doi.org/10.5061/dryad.w9ghx3fm7), LME (17\%) (figure 1), and encephalitis (13\%) (figures 2 and 3 and figure e-2, available from Dryad) were the most frequent neuroimaging findings. LME was seen on both postcontrast T1-weighted and FLAIR sequences and was even better visualized when delayed postcontrast FLAIR was performed. These signal abnormalities were not present on precontrast T1 or FLAIR images.
Among the 8 encephalitis, 2 cases of limbic encephalitis, 2 cases of radiologic acute hemorrhagic necrotizing encephalopathy, 2 cases of miscellaneous encephalitis, 1 case of radiologic $\mathrm{ADEM}$, and 1 case of CLOCC were described.

\section{CSF analysis}

Twenty-five (39\%) patients underwent a lumbar puncture: 7 in the encephalitis group, 8 in the LME group, 2 in the ischemic stroke group, and 8 in the normal brain MRI group.

CSF glucose was normal in all cases.

In the encephalitis group (table 3), 6 patients showed markers of inflammation: 4 had pleocytosis, 5 had high levels of protein, 2 had elevated immunoglobulin G, and another had oligoclonal bands that were identical in CSF and serum. In the LME group (table 3), 6 patients showed markers of inflammation: 2 had pleocytosis, 3 had high levels of protein, 2 
Table 2 Characteristics of patients with COVID-19 with acute ischemic stroke

\begin{tabular}{|c|c|c|c|c|c|c|c|c|c|}
\hline Sex & Age, y & Risk factors & Clinical presentation & $\begin{array}{l}\text { Days from COVID-19 } \\
\text { respiratory symptom } \\
\text { onset to ischemic } \\
\text { stroke symptom onset }\end{array}$ & $\begin{array}{l}\text { Treatment up to } \\
\text { this time point }\end{array}$ & $\begin{array}{l}\text { Arrhythmias (ECG } \\
\text { or echocardiography) }\end{array}$ & $\begin{array}{l}\text { Brain } \\
\text { MRI }\end{array}$ & $\begin{array}{l}\text { Large vessel } \\
\text { occlusion? }\end{array}$ & $\begin{array}{l}\text { D-dimers } \\
\text { (reference range }<400 \text { ), } \mu \mathrm{g} / \mathrm{L}\end{array}$ \\
\hline M & 86 & $\begin{array}{l}\text { Hypertension } \\
\text { Dyslipidemia }\end{array}$ & $\begin{array}{l}\text { Left hemiplegia/impaired } \\
\text { consciousness }\end{array}$ & 1 & Supportive & No & $\mathrm{LAl}$ & $\begin{array}{l}\text { Distal M1 occlusion } \\
\text { with thrombus }\end{array}$ & NR \\
\hline M & 71 & $\begin{array}{l}\text { Hypertension } \\
\text { Diabetes } \\
\text { mellitus }\end{array}$ & Left hemiplegia & 16 & Antibiotics & $\begin{array}{l}\text { Yes (previously } \\
\text { unknown) }\end{array}$ & $\mathrm{LAl}$ & $\begin{array}{l}\text { Distal M1 occlusion } \\
\text { with thrombus }\end{array}$ & 2,860 \\
\hline $\mathbf{F}$ & 74 & - & Bilateral pyramidal tract signs & 8 & $\begin{array}{l}\text { Antibiotics } \\
\text { Hydroxychloroquine }\end{array}$ & No & $\mathrm{WCl}$ & - & $>20,000$ \\
\hline M & 63 & Smoking & $\begin{array}{l}\text { Left-sided weakness/left-sided } \\
\text { sensory inattention }\end{array}$ & 14 & Antibiotics & $\begin{array}{l}\text { Yes (previously } \\
\text { unknown) }\end{array}$ & $\mathrm{LAl}$ & - & 1,000 \\
\hline M & 65 & $\begin{array}{l}\text { Hypertension } \\
\text { Diabetes } \\
\text { mellitus } \\
\text { Dyslipidemia } \\
\text { HOS }\end{array}$ & Impaired consciousness & 22 & Antibiotics & No & $\mathrm{WCl}$ & - & 1,570 \\
\hline $\mathbf{F}$ & 78 & Hypertension & Dysarthria & 3 & Supportive & No & $\mathrm{WCl}$ & - & 720 \\
\hline $\mathbf{F}$ & 75 & $\begin{array}{l}\text { Hypertension } \\
\text { Dyslipidemia } \\
\text { Atrial Fibrillation }\end{array}$ & $\begin{array}{l}\text { Aphasia/right hemiplegia/ } \\
\text { impaired consciousness/ } \\
\text { agitation }\end{array}$ & 6 & Supportive & NR & LAl & ICA occlusion & NR \\
\hline M & 79 & $\begin{array}{l}\text { Hypertension } \\
\text { Dyslipidemia } \\
\text { HOS }\end{array}$ & $\begin{array}{l}\text { Headaches/impaired } \\
\text { consciousness/confusion }\end{array}$ & 5 & Supportive & No & WCI & - & NR \\
\hline $\mathbf{F}$ & 71 & $\begin{array}{l}\text { Hypertension } \\
\text { Smoking } \\
\text { Atrial fibrillation }\end{array}$ & Left hemiplegia & 3 & Supportive & Yes & $\mathrm{LAl}$ & $\begin{array}{l}\text { Proximal M2 } \\
\text { occlusion }\end{array}$ & $>20,000$ \\
\hline M & 59 & $\begin{array}{l}\text { Hypertension } \\
\text { Smoking }\end{array}$ & Left hemiplegia/left facial droop & 1 & Supportive & No & $\mathrm{LAl}$ & $\begin{array}{l}\text { Proximal M1 } \\
\text { occlusion with } \\
\text { thrombus }\end{array}$ & 2,868 \\
\hline M & 66 & $\begin{array}{l}\text { Hypertension } \\
\text { Dyslipidemia } \\
\text { Diabetes } \\
\text { mellitus }\end{array}$ & $\begin{array}{l}\text { Left pyramidal tract signs/left } \\
\text { facial droop/aphasia }\end{array}$ & 4 & Supportive & No & $\mathrm{LAl}$ & ICA dissection & 5,227 \\
\hline M & 72 & $\begin{array}{l}\text { Dyslipidemia } \\
\text { Atrial fibrillation }\end{array}$ & Impaired consciousness & 15 & Antibiotics & Yes & $\mathrm{LAl}$ & - & 993 \\
\hline M & 78 & Hypertension & $\begin{array}{l}\text { Dysarthria/right-sided } \\
\text { weakness/right facial droop }\end{array}$ & 16 & Supportive & No & LAl & - & NR \\
\hline
\end{tabular}


had elevated immunoglobulin G, and 4 had oligoclonal bands that were identical in CSF and serum. In the ischemic stroke group, 1 patient had a high level of protein.

The RT-PCR SARS-CoV-2 analysis was negative in the 20 patients who were investigated. The analysis was not realized for 5 patients: 1 with a normal brain MRI, 2 with an ischemic stroke, 1 with encephalitis, and 1 with LME. Cultures for other viruses or bacteria were always negative when performed.

\section{Correlation analysis}

There were statistically significant differences between the various groups concerning age $(p=0.007)$, the presence of pyramidal tract signs $(p=0.02)$, agitation $(p=0.009)$, and respiratory status (ARDS) $(p=0.006)$ (table 1$)$.

The MCA showed that the ischemic stroke group could be distinguished from the 3 others, which largely overlap (figure 4). Most patients with ischemic stroke (numbers and dots in red on the plot) are located on the same lower-right half of the graph, indicating a commonality of symptoms. Those patients can be overall described as older with no ARDS, no oxygen requirement, no confusion, no disturbances of consciousness, and a lower death rate. The converse is true for the 3 other diagnoses that cannot be distinguished. Considering each clinical manifestation separately (figure e-3, available from Dryad, doi.org/10.5061/dryad.w9ghx3fm7), subjects can be distinguished mainly on the basis of a global pattern, depending on their oxygen requirement, seizure, sex, headaches, history of autoimmune disease, history of seizure, age, anosmia, confusion, and disturbances of consciousness.

\section{Discussion}

This is the first large, nationwide cohort of MRIs performed in patients with COVID-19 with neurologic manifestations.

The majority of patients had MRI abnormalities with serious and various findings beyond the severe respiratory disease (half of the patients had ARDS, and 11\% died): cerebrovascular disease (especially ischemic stroke; large artery infarctions more frequently than watershed cerebral infarctions), encephalitis (including limbic encephalitis, radiologic ADEM, CLOCC, and radiologic acute hemorrhagic necrotizing encephalopathy), and focal or even diffuse LME. The heterogeneity of the imaging abnormalities was underpinned by heterogeneous clinical manifestations, ranging from anosmia, ageusia, or headache to more severe findings such as confusion with agitation, loss of consciousness, and corticospinal tract signs. Some correlations were found between clinical and imaging findings, allowing the identification of clinicoradiologic profiles of patients with COVID-19 displaying neurologic manifestations.

Ischemic stroke was 1 kind of clinicoradiologic phenotype; it was an acute event, arising in older patients who more frequently had corticospinal tract signs but was less frequently 
Table 3 Characteristics of patients with COVID-19 with meningoencephalitis

\begin{tabular}{|c|c|c|c|c|c|c|}
\hline Sex & Age, $y$ & Clinical symptoms & $\begin{array}{l}\text { Days from COVID-19 } \\
\text { respiratory symptom } \\
\text { onset to brain MRI }\end{array}$ & Treatment up to this time point & CSF analysis & Imaging findings \\
\hline $\mathbf{F}$ & 71 & $\begin{array}{l}\text { Confusion/impaired } \\
\text { consciousness/agitation }\end{array}$ & 22 & $\begin{array}{l}\text { Oxygen therapy } \\
\text { Antibiotics } \\
\text { Lopinavir-ritonavir }\end{array}$ & $\begin{array}{l}0 \text { cell } \\
\uparrow \text { Total protein: } 0.57 \mathrm{~g} / \mathrm{L}\end{array}$ & $\begin{array}{l}\text { Miscellaneous encephalitis/diffusion } \\
\text { and T2/FLAIR hyperintensities } \\
\text { involving supratentorial WM }\end{array}$ \\
\hline$M$ & 64 & $\begin{array}{l}\text { Confusion/impaired } \\
\text { consciousness/agitation }\end{array}$ & 17 & $\begin{array}{l}\text { Oxygen therapy } \\
\text { Antibiotics } \\
\text { Lopinavir-ritonavir }\end{array}$ & $\begin{array}{l}40 \text { cells } / \mathrm{mm}^{3} \\
\uparrow \text { Total protein: } 1.1 \mathrm{~g} / \mathrm{L} \\
\uparrow \text { Immunoglobulin G: } 56 \mathrm{mg} / \mathrm{L}\end{array}$ & $\begin{array}{l}\text { Miscellaneous encephalitis/FLAIR } \\
\text { hyperintensity involving both middle } \\
\text { cerebellar peduncles }\end{array}$ \\
\hline$M$ & 56 & $\begin{array}{l}\text { Impaired consciousness/ } \\
\text { pathologic wakefulness when } \\
\text { sedation was stopped }\end{array}$ & 23 & $\begin{array}{l}\text { Admitted to ICU } \\
\text { Mechanical ventilation } \\
\text { Antibiotics }\end{array}$ & $\begin{array}{l}1 \text { cell/mm } \mathrm{mm}^{3} \\
\uparrow \text { Total protein: } 2 \mathrm{~g} / \mathrm{L} \\
\uparrow \text { Immunoglobulin G: } 169 \mathrm{mg} / \mathrm{L} \\
\text { Oligoclonal bands identical in CSF and serum }\end{array}$ & $\begin{array}{l}\text { Radiologic acute hemorrhagic } \\
\text { necrotizing encephalopathy }\end{array}$ \\
\hline M & 66 & $\begin{array}{l}\text { Impaired consciousness/ } \\
\text { pathologic wakefulness when } \\
\text { sedation was stopped }\end{array}$ & 34 & $\begin{array}{l}\text { Admitted to ICU } \\
\text { Mechanical ventilation } \\
\text { Antibiotics } \\
\text { Lopinavir-ritonavir }\end{array}$ & NR & $\begin{array}{l}\text { Radiologic acute hemorrhagic } \\
\text { necrotizing encephalopathy }\end{array}$ \\
\hline$M$ & 55 & $\begin{array}{l}\text { Headaches/dizziness/impaired } \\
\text { consciousness }\end{array}$ & 3 & - & $\begin{array}{l}7 \text { cells } / \mathrm{mm}^{3} \\
\uparrow \text { Total protein: } 0.56 \mathrm{~g} / \mathrm{L}\end{array}$ & CLOCC \\
\hline M & 56 & Headaches & 20 & $\begin{array}{l}\text { Admitted to ICU } \\
\text { Mechanical ventilation } \\
\text { Antibiotics }\end{array}$ & $\begin{array}{l}3 \text { cells } / \mathrm{mm}^{3} \\
\text { Total protein: } 0.24 \mathrm{~g} / \mathrm{L}\end{array}$ & Left limbic encephalitis \\
\hline$M$ & 58 & Ataxia & 21 & $\begin{array}{l}\text { Admitted to ICU } \\
\text { Mechanical ventilation } \\
\text { Antibiotics } \\
\text { Hydroxychloroquine }\end{array}$ & $\begin{array}{l}4 \text { cells } / \mathrm{mm}^{3} \\
\uparrow \text { Total protein: } 0.77 \mathrm{~g} / \mathrm{L}\end{array}$ & Left limbic encephalitis \\
\hline M & 60 & $\begin{array}{l}\text { Confusion/impaired } \\
\text { consciousness/agitation }\end{array}$ & 13 & $\begin{array}{l}\text { Admitted to ICU } \\
\text { Mechanical ventilation } \\
\text { Antibiotics } \\
\text { Hydroxychloroquine }\end{array}$ & $\begin{array}{l}0 \text { cell } \\
\text { Total protein: } 0.3 \mathrm{~g} / \mathrm{L}\end{array}$ & Radiologic ADEM \\
\hline $\mathbf{F}$ & 51 & Movement disorders/agitation & 16 & - & $\begin{array}{l}5 \text { cells } \\
\uparrow \text { Total protein: } 0.66 \mathrm{~g} / \mathrm{L}\end{array}$ & Focal LME \\
\hline $\mathbf{F}$ & 59 & Headaches/dizziness & 18 & $\begin{array}{l}\text { Admitted to ICU } \\
\text { Mechanical ventilation } \\
\text { Antibiotics } \\
\text { Lopinavir-ritonavir }\end{array}$ & NR & Focal LME \\
\hline M & 62 & $\begin{array}{l}\text { Confusion/impaired } \\
\text { consciousness/agitation }\end{array}$ & 19 & $\begin{array}{l}\text { Admitted to ICU } \\
\text { Mechanical ventilation } \\
\text { Antibiotics } \\
\text { Lopinavir-ritonavir }\end{array}$ & $\begin{array}{l}0 \text { cell } \\
\text { Total protein: } 0.23 \mathrm{~g} / \mathrm{L} \\
\text { Immunoglobulin } \mathrm{G}: 33 \mathrm{mg} / \mathrm{L} \\
\text { Oligoclonal bands identical in CSF and serum }\end{array}$ & Diffuse LME \\
\hline
\end{tabular}




\begin{tabular}{|c|c|c|c|c|c|c|}
\hline Sex & Age, y & Clinical symptoms & $\begin{array}{l}\text { Days from COVID-19 } \\
\text { respiratory symptom } \\
\text { onset to brain MRI }\end{array}$ & Treatment up to this time point & CSF analysis & Imaging findings \\
\hline M & 78 & Agitation & 15 & $\begin{array}{l}\text { Admitted to ICU } \\
\text { Mechanical ventilation } \\
\text { Antibiotics } \\
\text { Lopinavir-ritonavir }\end{array}$ & NR & Focal LME \\
\hline M & 72 & $\begin{array}{l}\text { Impaired consciousness/bilateral } \\
\text { pyramidal tract signs }\end{array}$ & 20 & $\begin{array}{l}\text { Oxygen therapy } \\
\text { Antibiotics } \\
\text { Lopinavir-ritonavir } \\
\text { Hydroxychloroquine }\end{array}$ & $\begin{array}{l}0 \text { cell } \\
\text { Total protein: } 0.23 \mathrm{~g} / \mathrm{L} \\
\text { Immunoglobulin G: } 17 \mathrm{mg} / \mathrm{L} \\
\text { Oligoclonal bands identical in CSF and serum }\end{array}$ & Focal LME \\
\hline$M$ & 61 & $\begin{array}{l}\text { Impaired consciousness/bilateral } \\
\text { pyramidal tract signs/confusion/ } \\
\text { agitation }\end{array}$ & 14 & $\begin{array}{l}\text { Oxygen therapy } \\
\text { Antibiotics } \\
\text { Hydroxychloroquine }\end{array}$ & $\begin{array}{l}1 \text { cell//mm }{ }^{3} \\
\text { Total protein: } 0.23 \mathrm{~g} / \mathrm{L} \\
\text { Immunoglobulin G: } 17 \mathrm{mg} / \mathrm{L}\end{array}$ & Focal LME \\
\hline M & 66 & $\begin{array}{l}\text { Confusion/impaired } \\
\text { consciousness/agitation }\end{array}$ & 22 & $\begin{array}{l}\text { Admitted to ICU } \\
\text { Mechanical ventilation } \\
\text { Antibiotics }\end{array}$ & NR & Focal LME \\
\hline $\mathbf{F}$ & 53 & $\begin{array}{l}\text { Confusion/impaired } \\
\text { consciousness }\end{array}$ & 29 & $\begin{array}{l}\text { Admitted to ICU } \\
\text { Mechanical ventilation } \\
\text { Antibiotics } \\
\text { Lopinavir-ritonavir }\end{array}$ & $\begin{array}{l}0 \text { cell } \\
\text { Total protein: } 0.29 \mathrm{~g} / \mathrm{L} \\
\text { Immunoglobulin G: } 21 \mathrm{mg} / \mathrm{L}\end{array}$ & Focal LME \\
\hline $\mathbf{F}$ & 64 & Bilateral pyramidal tract signs & 11 & $\begin{array}{l}\text { Admitted to ICU } \\
\text { Mechanical ventilation } \\
\text { Antibiotics }\end{array}$ & $\begin{array}{l}2 \text { cells } / \mathrm{mm}^{3} \\
\text { Total protein: } 0.30 \mathrm{~g} / \mathrm{L} \\
\text { Immunoglobulin G: } 15 \mathrm{mg} / \mathrm{L} \\
\text { Oligoclonal bands identical in CSF and serum. }\end{array}$ & Focal LME \\
\hline $\mathbf{F}$ & 77 & $\begin{array}{l}\text { Bilateral pyramidal syndrome/ } \\
\text { confusion/agitation }\end{array}$ & 30 & $\begin{array}{l}\text { Admitted to ICU } \\
\text { Mechanical ventilation } \\
\text { Antibiotics } \\
\text { Lopinavir-ritonavir } \\
\text { Hydroxychloroquine }\end{array}$ & $\begin{array}{l}1 \text { cell/mm } \mathrm{mm}^{3} \\
\uparrow \text { Total protein: } 0.80 \mathrm{~g} / \mathrm{L} \\
\uparrow \text { Immunoglobulin G: } 58 \mathrm{mg} / \mathrm{L}\end{array}$ & Diffuse LME \\
\hline $\mathbf{F}$ & 81 & $\begin{array}{l}\text { Confusion/impaired } \\
\text { consciousness/agitation }\end{array}$ & 20 & $\begin{array}{l}\text { Admitted to ICU } \\
\text { Mechanical ventilation } \\
\text { Antibiotics } \\
\text { Hydroxychloroquine }\end{array}$ & $\begin{array}{l}80 \text { cells } / \mathrm{mm}^{3} \\
\uparrow \text { Total protein: } 0.62 \mathrm{~g} / \mathrm{L} \\
\uparrow \text { Immunoglobulin G: } 38 \mathrm{mg} / \mathrm{L} \\
\text { Oligoclonal bands identical in CSF and serum }\end{array}$ & Focal LME \\
\hline
\end{tabular}

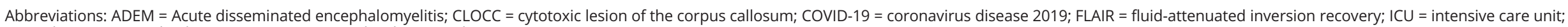
$\mathrm{LME}=$ leptomeningeal enhancement; $\mathrm{NR}=$ not realized; $\mathrm{WM}=$ white matter 


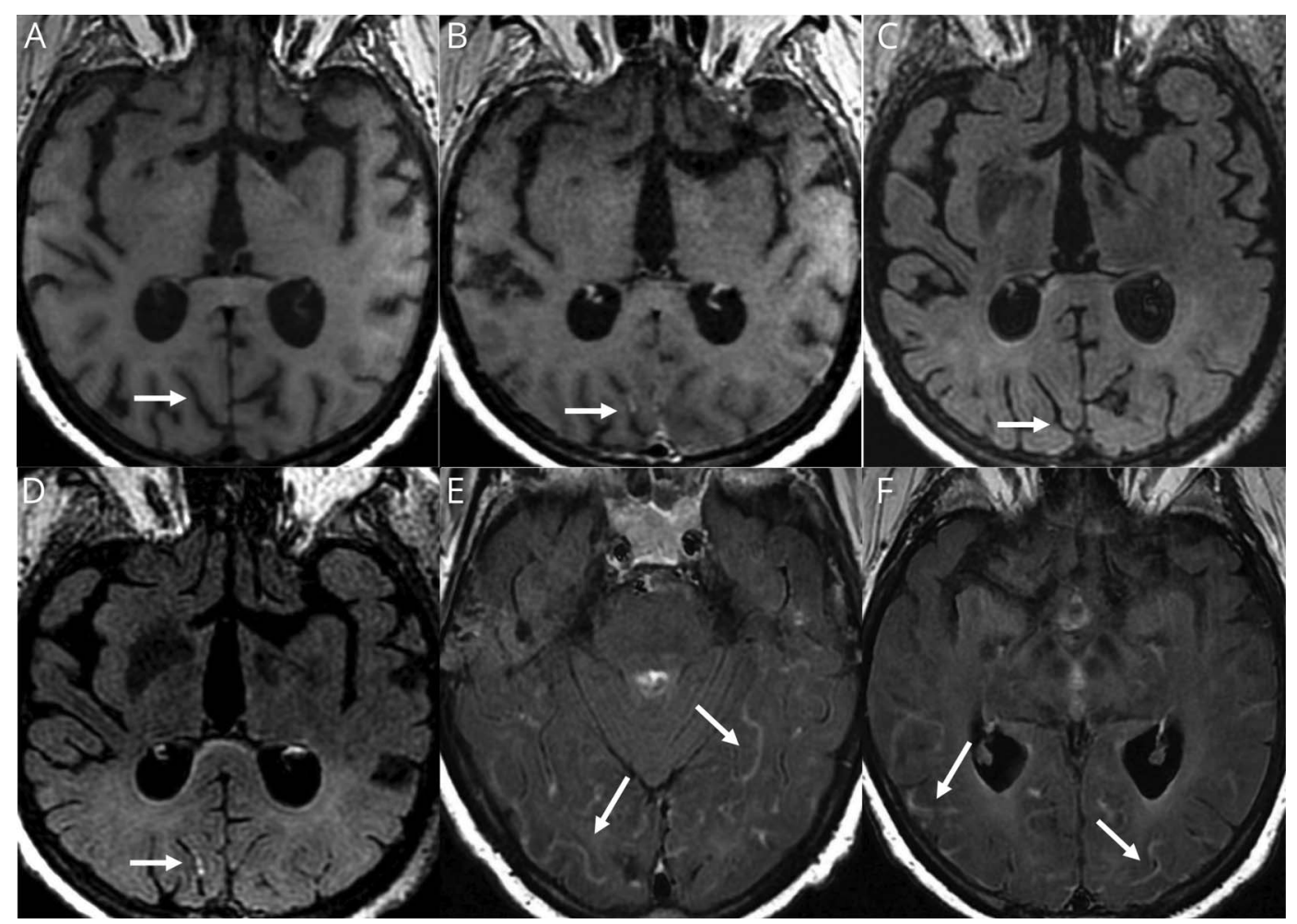

Axial T1 (A) before and (B) 5 minutes after contrast, axial FLAIR (C) before and (D) immediately after contrast, and (E and F) delayed (10 minutes) postcontrast axial fluid-attenuated inversion recovery (FLAIR) weighted MRIs. Woman 77 years of age: diffuse leptomeningeal linear FLAIR and T1 contrast enhancement (arrows) not visible on precontrast T1 and FLAIR (arrows) but seen better on delayed postcontrast FLAIR weighted MRIs (E and F).

requiring oxygen or presenting an ARDS. This profile could be distinguished from the 2 others, LME and encephalitis. The encephalitis profile affected younger patients and seemed to be particularly severe because it was associated with the need for oxygen, ARDS, and death.

Stroke patients less frequently had ARDS, and this result is in agreement with the 6 patients with stroke previously reported in that only 2 patients were admitted to ICUs. ${ }^{16}$ One may hypothesize that strokes in patients with COVID-19 could be due to procoagulant events leading to thrombosis ${ }^{17}$ rather than to the systemic inflammatory process that accompanies ARDS, which is also directed against the CNS. However, this needs to be assessed by further studies dedicated to stroke and thrombosis in patients with COVID-19.

In our study, 17 (27\%) patients had an acute ischemic stroke, as was previously reported with SARS-CoV, ${ }^{18}$ Middle East respiratory syndrome coronavirus (MERS-CoV), ${ }^{19}$ and SARS-CoV-2, ${ }^{11,16,17}$ and among them, 11 had large artery infarctions (including 6 proximal artery occlusions, 2 cases of internal carotid artery dissection or occlusion) and 6 had watershed cerebral infarctions. For 15 of 17 patients with an ischemic stroke, the respiratory symptoms related to COVID19 had begun before this acute event, while stroke preceded respiratory symptoms by 2 days for 2 patients.
Several mechanisms are likely to be associated. It is now known that SARS-CoV-2 could directly lead to myocardial injury, promoting cardiac arrhythmias associated with embolic events. ${ }^{20}$ Six of our patients had arrhythmias, which were previously unknown for 3 of them. In the same way, a severe acute myocardial injury may be associated with a decrease in brain perfusion and therefore with watershed cerebral infarctions. As previously mentioned, it is acknowledged that viruses, particularly SARS-CoV-2, ${ }^{21}$ are associated with an increase of prothrombotic events such as ischemic stroke. ${ }^{22,23}$ Thereby, viral infections may elevate procoagulant markers, leading to thrombosis, disseminated intravascular coagulation, and hemorrhagic events. ${ }^{23}$ As Beyrouti et al. ${ }^{16}$ recently mentioned, all our patients tested showed elevated D-dimers, markedly elevated (>1000 $\mu \mathrm{g} / \mathrm{L})$ for 10 of the 11 patients tested.

Varicella zoster virus is also associated with direct vascular involvement and eventually arteritis promoting ischemic stroke events. ${ }^{22}$ Furthermore, the more severe critically ill patients hospitalized in ICUs have probably had hypoxemia and hypotension, leading to brain injuries. ${ }^{18}$

Of the 36 abnormal MRIs, 8 diagnoses of encephalitis were made, and LME was described, especially on postcontrast T1weighted and FLAIR, in 11 patients, either focal (single focus 


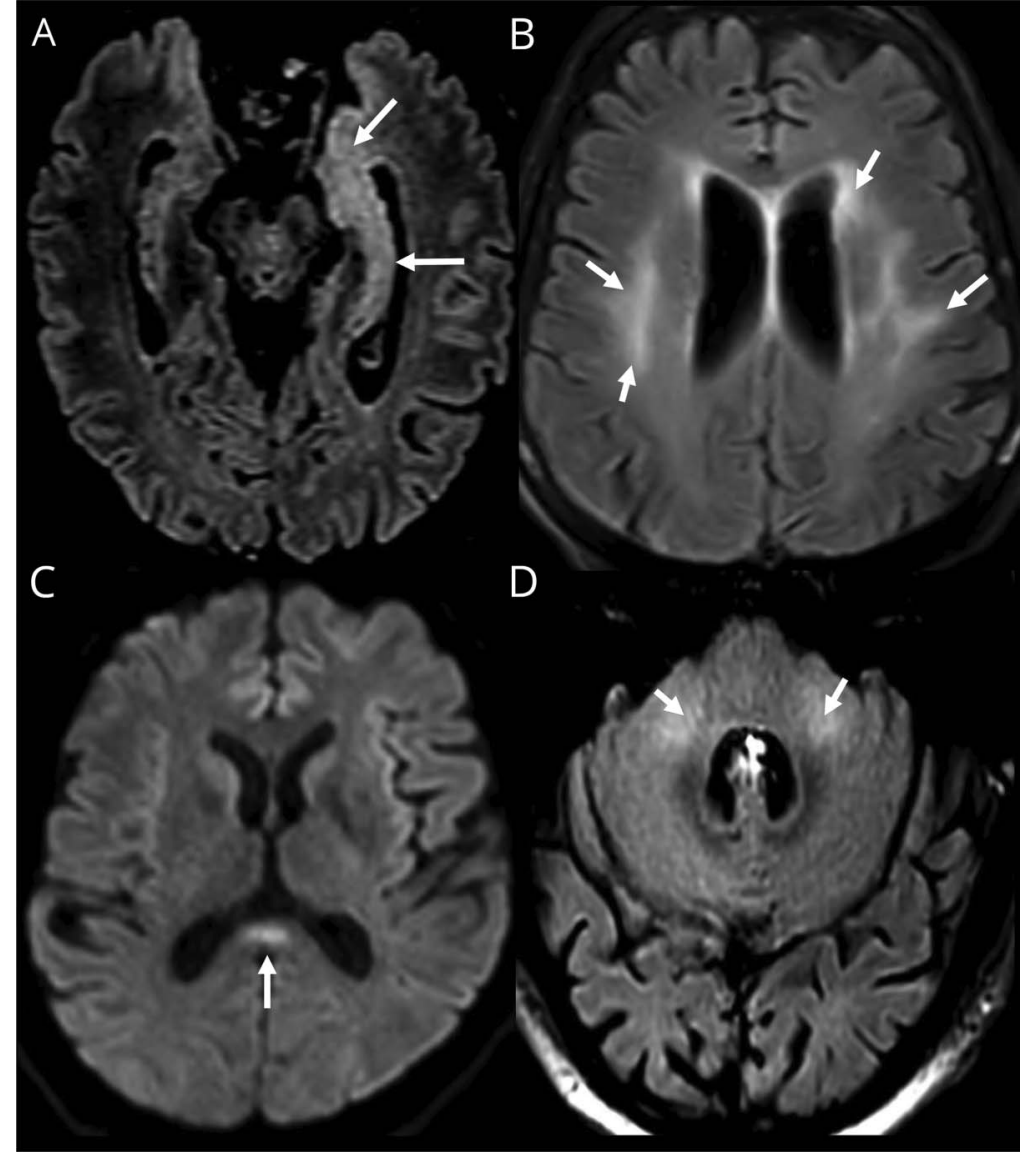

(A, B, D) Axial fluid-attenuated inversion recovery (FLAIR) and (C) diffusion-weighted MRIs. (A) Man 56 years of age: left hippocampus and amygdala FLAIR hyperintensity. (B) Woman 71 years of age: periventricular and subcortical white matter FLAIR confluent hyperintensities. (C) Man 55 years of age: corpus callosum splenium diffusion hyperintensity. (D) Man 64 years of age: FLAIR middle cerebellar peduncle hyperintensity. vs multiple foci) or diffuse, and preferentially located in the posterior, supratentorial regions of the brain.

Two main pathophysiologic hypotheses can be advanced to explain the neuroimaging findings in the inflammatory profile group. First, SARS-CoV-2 may have a neuroinvasive potential similar to other hCoVs because this family of viruses is related to each other genetically. It is not clear if the virus can infiltrate the CNS with active replication and direct damage to brain cells (viral encephalitis), as observed with other viruses such as herpes simplex virus. Likewise, viral meningitis due to direct infiltration of the virus into the CSF may also be considered because it was previously reported with SARS-CoV-1. Indeed, SARS-CoV-1 RNA was detected in the CSF of 2 patients with seizures. ${ }^{24,25} \mathrm{~A}$ recent case report ${ }^{10}$ has described for the first time a case of seizures with the detection of SARS-CoV-2 RNA in the CSF. Similarly, leptomeningeal inflammation may be present adjacent to subpial cortical lesions in the case of viral meningoencephalitis. In the case of viral encephalitis, CSF analysis usually demonstrates lymphocytic pleocytosis. ${ }^{26}$ In addition, the CSF protein level is typically elevated in viral encephalitis. CSF viral RT-PCR is usually positive but can be negative if done too early. This was not the case in our series, and our results are in accordance with recently published data that demonstrated an absence of CSF pleocytosis and negative SARS-CoV-2 RT-PCR (5 of 5 patients) but elevated protein level (4 of 5 patients) in patients presenting cerebral MRI cortical abnormalities. ${ }^{13}$ MRI pictures of viral encephalitis vary with causal pathogen. Nevertheless, viral encephalitis usually involves cerebral GM with diffusion restriction and can be associated with intralesional and diffuse leptomeningeal contrast enhancement. This was not the case in our series and did not argue for the direct effect of the virus. It is all the more likely that the direct detection of SARS-CoV-2 RNA by RT-PCR was always negative in all our CSF samples.

An alternative hypothesis appears more relevant: the neurovirulence of hCoVs, especially MERS-CoV, seems to be a consequence of immune-mediated processes. ${ }^{19,27-29}$ Indeed, ADEM and Bickerstaff brainstem encephalitis, which were described with MERS-CoV, ${ }^{18-27}$ are 2 examples of autoimmune demyelinating diseases resulting from a postinfectious or parainfectious process. A recent case report ${ }^{9}$ has described a case of acute hemorrhagic necrotizing encephalopathy (which is the most severe form of ADEM) associated with COVID-19, which strengthens the hypothesis of a predominant immunologic mechanism. In our cohort, we also described 2 cases of 


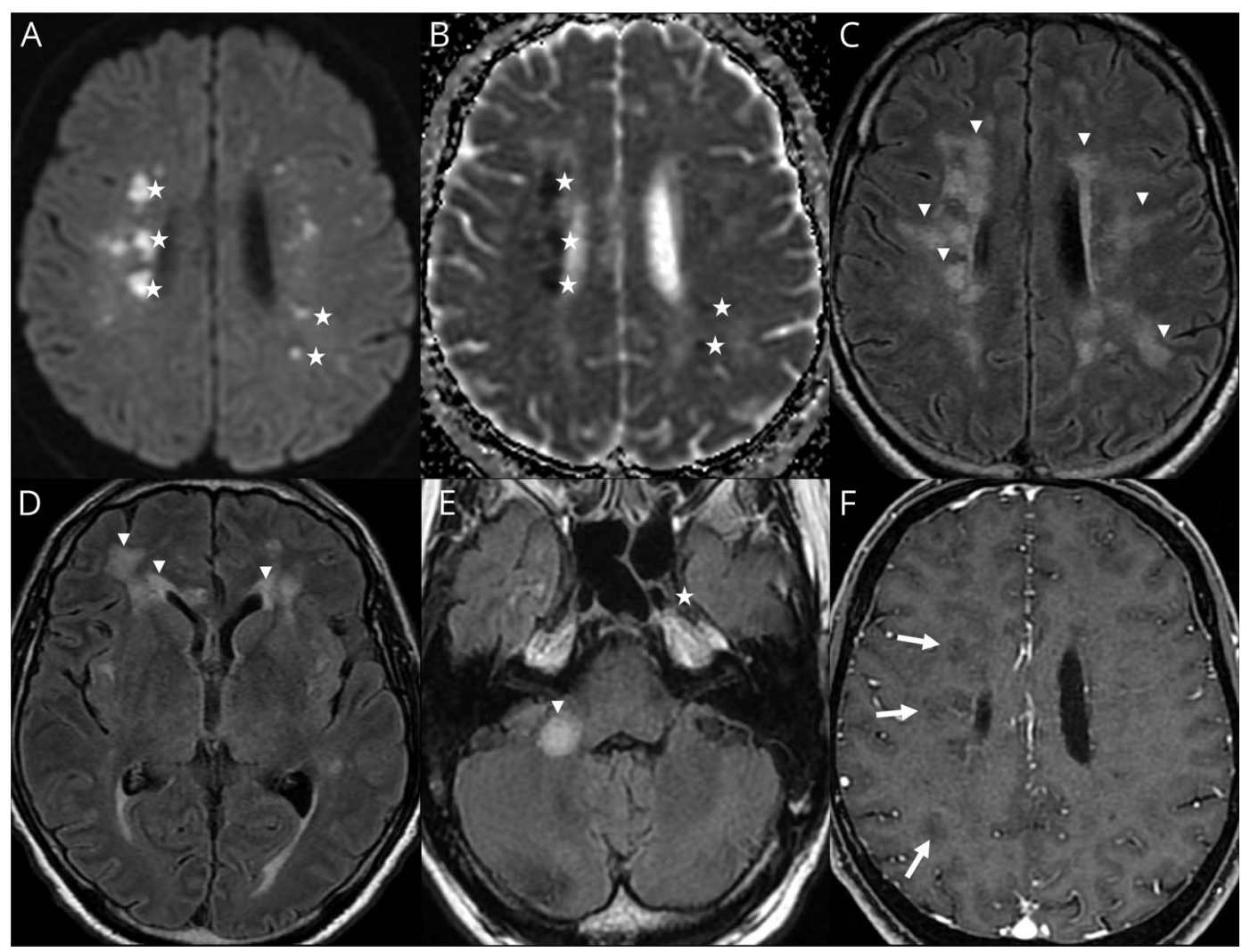

( $A, E, I)$ Axial fluid-attenuated inversion recovery (FLAIR), (B, F, J) axial diffusion, (B, F, J) apparent diffusion coefficient (ADC) map, and (D, H, L) postcontrast T1 weighted MRIs. Man 60 years of age: subcortical, periventricular, corpus callosum, and posterior fossa white matter FLAIR hyperintensities without contrast enhancement (arrows). Some lesions appear hyperintense on diffusion-weighted MRIs, with decreased ADC corresponding to cytotoxic edema (stars). Other lesions present an ADC increase corresponding to vasogenic edema (cross).

limbic encephalitis and 1 case of CLOCC. Concerning the latter, no treatment had been started or stopped in previous weeks. Thus, $75 \%$ of encephalitis cases in our cohort (limbic encephalitis, CLOCC, radiologic ADEM, radiologic acute hemorrhagic necrotizing encephalopathy) are possibly considered immune-mediated diseases. Therefore, SARS-CoV-2mediated disease is driven largely by immunologic processes, and the same mechanisms could explain LME. Indeed, the arachnoid and pial membranes form the leptomeninges, and a significant amount of antigen-presenting cells are present in the subarachnoid space. ${ }^{30}$ Thus, initial immune activation occurs in the subarachnoid space, which is a site for antigen presentation, lymphocyte accumulation and proliferation, and antibody production. ${ }^{30}$ All lead to an important local inflammatory infiltrate with a blood-CSF barrier disruption, which can also explain LME. Thus, LME can be linked to inflammatory or immunologic responses, as previously described in animal models of autoimmune encephalomyelitis, ${ }^{31}$ with some neurotropic viruses such as human T-cell leukemia virus and $\mathrm{HIV}^{31}$ and in several immune-mediated neurologic diseases. ${ }^{31}$ Moreover, a very similar intracranial pattern has been described in an animal study in piglets affected by gastroenteritis coronavirus. ${ }^{32}$ Indeed, histology demonstrated diffuse pia matter gliosis with mild congestion of the meningeal and parenchymal vessels with neuronal degeneration, located mostly in posterior parietooccipital lobes. ${ }^{24}$ Postcontrast FLAIR is the best sequence to highlight LME, but a potential pitfall is inhalation of increased levels of oxygen by patients who are intubated, which may increase subarachnoid space signal intensity noted on FLAIR images within the basal cisterns and sulcus along the cerebral convexities. ${ }^{33}$ That is why we have chosen in this situation to acquire systematically precontrast and postcontrast FLAIR sequences to avoid misinterpretation of FLAIR hyperintensity within the subarachnoid spaces and not to misdescribe a meningeal enhancement. For our 11 patients with LME, no precontrast FLAIR signal abnormalities were visible in the subarachnoid spaces.

Our study has several limitations, mainly due to its multicenter and retrospective design. First, brain MRI protocols were dictated by clinical need, and the patterns of working could be different among the 11 centers, even if neuroradiologists are used to work together. Thus, $36 \%$ of the MRIs were performed without administration of gadolinium-based contrast agents, notably preventing the detection of LME, therefore probably underestimating it. Moreover, LMEs are very subtle neuroimaging findings, which need the realization of delayed postcontrast FLAIR sequences, which were not done in the vast 


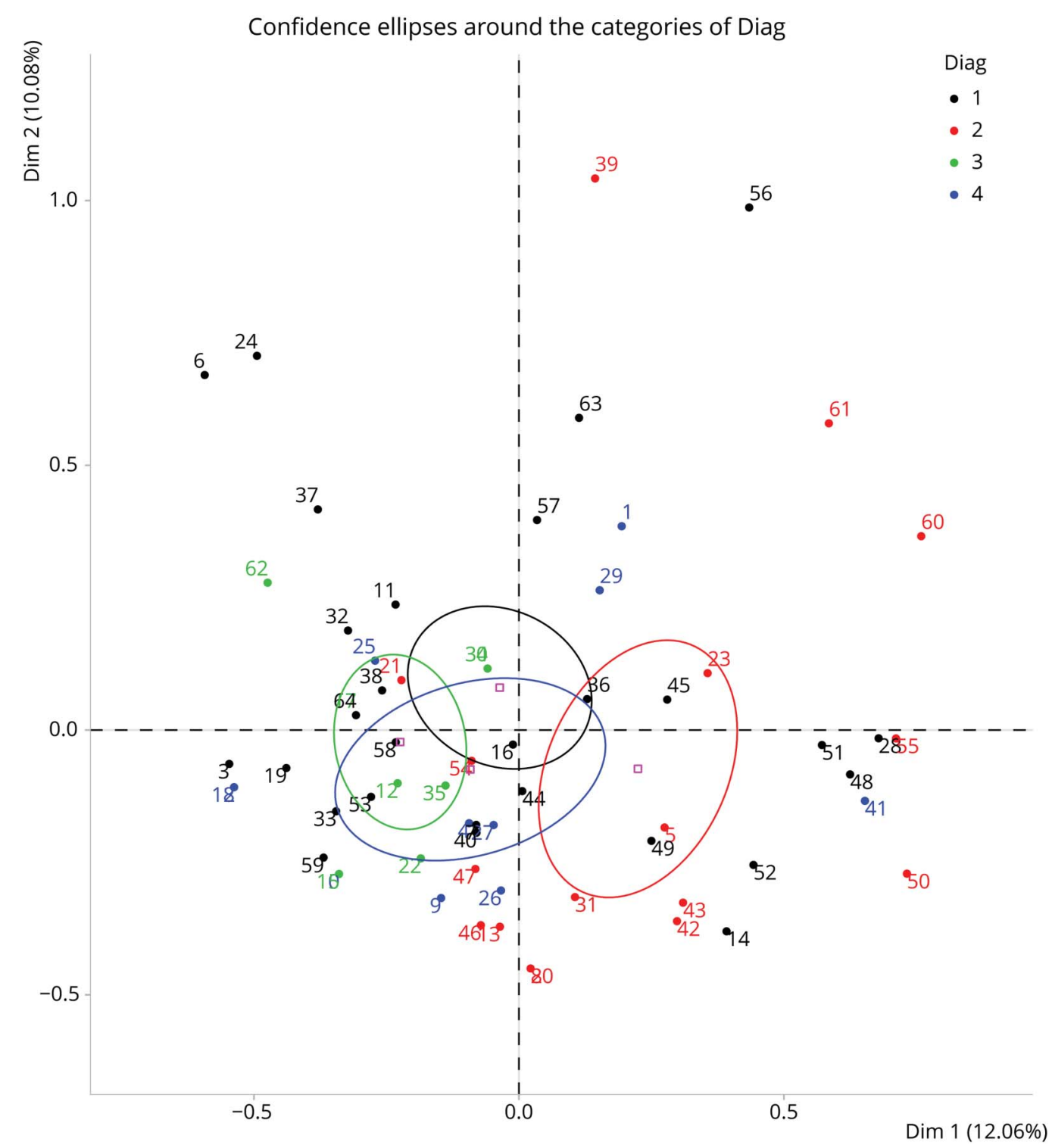

The ischemic stroke group (red) can be distinguished from the 3 others, which largely overlap. Most patients with ischemic stroke (numbers and dots in red on the plot) are located on the same lower-right half of the graph, indicating a commonality of symptoms. Diag 1 (black) = normal brain MRl; Diag 2 (red) = ischemic stroke; Diag 3 (green) = encephalitis; Diag 4 (blue) = leptomeningeal enhancement.

majority of the centers. Second, we did not realize a follow-up MRI, and some abnormalities could have appeared during follow-up. Third, outcomes were not available for all patients at the time of writing. Thus, the mortality rate is probably underestimated in our cohort. Fourth, although patients with COVID-19 may develop a wide range of neurologic symptoms, which can be associated with ischemic stroke or encephalitis, it is difficult to state without a controlled general neurologic population that such events are more frequent in patients with COVID-19. However, it now seems well established that thrombotic events are particularly frequent in patients with COVID-19. ${ }^{21}$ Moreover, encephalitis, which is a rare disorder in the general population, ${ }^{34}$ was surprisingly frequent in our population.
In this large multicentric national cohort, most patients with COVID-19 (56\%) with neurologic manifestations had brain MRI abnormalities such as ischemic stroke, LME, and encephalitis. Because the detection of LME suggests the abnormality of brain MRI, it would be interesting to realize systematically postcontrast FLAIR acquisition in patients with COVID-19.

Concerning the cases of encephalitis and LME, even if a direct viral origin cannot be eliminated, the pathophysiology of brain damage related to SARS-COV-2 seems rather to involve an inflammatory or autoimmune response. The knowledge of the various clinicoradiologic manifestations of COVID-19 could be helpful for the best care of the patients and our understanding of the disease. In addition to SARS, cytokine 
storm syndrome, and heart failure, brain injuries may contribute to increased mortality. This highlights the importance of neurologic evaluation, especially for patients hospitalized in ICU with clinical deterioration or worsening of their symptoms, which can be associated with an acute neurologic event.

\section{Acknowledgment}

The authors thank Marie Cécile Henry Feugeas for her work in data acquisition for this study.

\section{Study funding}

No targeted funding reported.

\section{Disclosure}

The authors report no disclosures relevant to the manuscript. Go to Neurology.org/N for full disclosures.

\section{Publication history}

Received by Neurology April 28, 2020. Accepted in final form June 9, 2020.

Appendix Authors

\begin{tabular}{|c|c|c|}
\hline Name & Location & Contribution \\
\hline $\begin{array}{l}\text { Stéphane } \\
\text { Kremer, MD, } \\
\text { PhD }\end{array}$ & $\begin{array}{l}\text { University Hospital of } \\
\text { Strasbourg, France }\end{array}$ & $\begin{array}{l}\text { Designed and conceptualized } \\
\text { the study; acquisition of data; } \\
\text { interpreted the data; drafted } \\
\text { the manuscript for } \\
\text { intellectual content }\end{array}$ \\
\hline $\begin{array}{l}\text { François Lersy, } \\
\text { MD }\end{array}$ & $\begin{array}{l}\text { University Hospital of } \\
\text { Strasbourg, France }\end{array}$ & $\begin{array}{l}\text { Designed and conceptualized } \\
\text { the study; acquisition of data; } \\
\text { interpreted the data; drafted } \\
\text { the manuscript for } \\
\text { intellectual content }\end{array}$ \\
\hline $\begin{array}{l}\text { Mathieu } \\
\text { Anheim, MD, } \\
\text { PhD }\end{array}$ & $\begin{array}{l}\text { University Hospital of } \\
\text { Strasbourg, France }\end{array}$ & $\begin{array}{l}\text { Designed and conceptualized } \\
\text { the study; interpreted the } \\
\text { data; revised the manuscript } \\
\text { for intellectual content }\end{array}$ \\
\hline $\begin{array}{l}\text { Hamid Merdji, } \\
\text { MD }\end{array}$ & $\begin{array}{l}\text { University Hospital of } \\
\text { Strasbourg, France }\end{array}$ & $\begin{array}{l}\text { Acquisition of data; revised } \\
\text { the manuscript for } \\
\text { intellectual content }\end{array}$ \\
\hline $\begin{array}{l}\text { Maleka } \\
\text { Schenck, MD }\end{array}$ & $\begin{array}{l}\text { University Hospital of } \\
\text { Strasbourg, France }\end{array}$ & $\begin{array}{l}\text { Acquisition of data; revised } \\
\text { the manuscript for } \\
\text { intellectual content }\end{array}$ \\
\hline $\begin{array}{l}\text { Hélène } \\
\text { Oesterlé, MD }\end{array}$ & $\begin{array}{l}\text { Hospital of Colmar, } \\
\text { France }\end{array}$ & $\begin{array}{l}\text { Acquisition of data; revised } \\
\text { the manuscript for } \\
\text { intellectual content }\end{array}$ \\
\hline $\begin{array}{l}\text { Federico } \\
\text { Bolognini, MD }\end{array}$ & $\begin{array}{l}\text { Hospital of Colmar, } \\
\text { France }\end{array}$ & $\begin{array}{l}\text { Acquisition of data; revised } \\
\text { the manuscript for } \\
\text { intellectual content }\end{array}$ \\
\hline $\begin{array}{l}\text { Julien Messie, } \\
\text { MD }\end{array}$ & $\begin{array}{l}\text { Hospital of Colmar, } \\
\text { France }\end{array}$ & $\begin{array}{l}\text { Acquisition of data; revised } \\
\text { the manuscript for } \\
\text { intellectual content }\end{array}$ \\
\hline $\begin{array}{l}\text { Antoine Khalil, } \\
\text { MD, PhD }\end{array}$ & $\begin{array}{l}\text { Bichat Hospital, Paris, } \\
\text { France }\end{array}$ & $\begin{array}{l}\text { Acquisition of data; revised } \\
\text { the manuscript for } \\
\text { intellectual content }\end{array}$ \\
\hline $\begin{array}{l}\text { Augustin } \\
\text { Gaudemer, MD }\end{array}$ & $\begin{array}{l}\text { Bichat Hospital, Paris, } \\
\text { France }\end{array}$ & $\begin{array}{l}\text { Acquisition of data; revised } \\
\text { the manuscript for } \\
\text { intellectual content }\end{array}$ \\
\hline
\end{tabular}

Appendix (continued)

\begin{tabular}{|c|c|c|}
\hline Name & Location & Contribution \\
\hline $\begin{array}{l}\text { Sophie Carré, } \\
\text { MD }\end{array}$ & $\begin{array}{l}\text { Hospital of } \\
\text { Haguenau, France }\end{array}$ & $\begin{array}{l}\text { Acquisition of data; revised } \\
\text { the manuscript for } \\
\text { intellectual content }\end{array}$ \\
\hline $\begin{array}{l}\text { Manel Alleg, } \\
\text { MD }\end{array}$ & $\begin{array}{l}\text { Hospital of } \\
\text { Haguenau, France }\end{array}$ & $\begin{array}{l}\text { Acquisition of data; revised } \\
\text { the manuscript for } \\
\text { intellectual content }\end{array}$ \\
\hline $\begin{array}{l}\text { Claire Lecocq, } \\
\text { MD }\end{array}$ & $\begin{array}{l}\text { Hospital of } \\
\text { Haguenau, France }\end{array}$ & $\begin{array}{l}\text { Acquisition of data; revised } \\
\text { the manuscript for } \\
\text { intellectual content }\end{array}$ \\
\hline $\begin{array}{l}\text { Emmanuelle } \\
\text { Schmitt, MD }\end{array}$ & $\begin{array}{l}\text { University Hospital of } \\
\text { Nancy, France }\end{array}$ & $\begin{array}{l}\text { Acquisition of data; revised } \\
\text { the manuscript for } \\
\text { intellectual content }\end{array}$ \\
\hline $\begin{array}{l}\text { René } \\
\text { Anxionnat, } \\
\text { MD, PhD }\end{array}$ & $\begin{array}{l}\text { University Hospital of } \\
\text { Nancy, France }\end{array}$ & $\begin{array}{l}\text { Acquisition of data; revised } \\
\text { the manuscript for } \\
\text { intellectual content }\end{array}$ \\
\hline $\begin{array}{l}\text { François Zhu, } \\
\text { MD }\end{array}$ & $\begin{array}{l}\text { University Hospital of } \\
\text { Nancy, France }\end{array}$ & $\begin{array}{l}\text { Acquisition of data; revised } \\
\text { the manuscript for } \\
\text { intellectual content }\end{array}$ \\
\hline $\begin{array}{l}\text { Lavinia Jager, } \\
\text { MD }\end{array}$ & $\begin{array}{l}\text { Hospital of Forbach, } \\
\text { France }\end{array}$ & $\begin{array}{l}\text { Acquisition of data; revised } \\
\text { the manuscript for } \\
\text { intellectual content }\end{array}$ \\
\hline $\begin{array}{l}\text { Patrick Nesser, } \\
\text { MD }\end{array}$ & $\begin{array}{l}\text { Hospital of Forbach, } \\
\text { France }\end{array}$ & $\begin{array}{l}\text { Acquisition of data; revised } \\
\text { the manuscript for } \\
\text { intellectual content }\end{array}$ \\
\hline $\begin{array}{l}\text { Yannick Talla } \\
\text { Mba, MD }\end{array}$ & $\begin{array}{l}\text { Hospital of Forbach, } \\
\text { France }\end{array}$ & $\begin{array}{l}\text { Acquisition of data; revised } \\
\text { the manuscript for } \\
\text { intellectual content }\end{array}$ \\
\hline $\begin{array}{l}\text { Ghazi } \\
\text { Hmeydia, MD }\end{array}$ & $\begin{array}{l}\text { Saint-Anne hospital, } \\
\text { Paris, France }\end{array}$ & $\begin{array}{l}\text { Acquisition of data; revised } \\
\text { the manuscript for } \\
\text { intellectual content }\end{array}$ \\
\hline $\begin{array}{l}\text { Joseph } \\
\text { Benzakoun, } \\
\text { MD }\end{array}$ & $\begin{array}{l}\text { Saint-Anne hospital, } \\
\text { Paris, France }\end{array}$ & $\begin{array}{l}\text { Acquisition of data; revised } \\
\text { the manuscript for } \\
\text { intellectual content }\end{array}$ \\
\hline $\begin{array}{l}\text { Catherine } \\
\text { Oppenheim, } \\
\text { MD, PhD }\end{array}$ & $\begin{array}{l}\text { Saint-Anne Hospital, } \\
\text { Paris, France }\end{array}$ & $\begin{array}{l}\text { Acquisition of data; revised } \\
\text { the manuscript for } \\
\text { intellectual content }\end{array}$ \\
\hline $\begin{array}{l}\text { Jean- } \\
\text { Christophe } \\
\text { Ferré, MD, PhD }\end{array}$ & $\begin{array}{l}\text { University Hospital of } \\
\text { Rennes, France }\end{array}$ & $\begin{array}{l}\text { Acquisition of data; revised } \\
\text { the manuscript for } \\
\text { intellectual content }\end{array}$ \\
\hline $\begin{array}{l}\text { Adel Maamar, } \\
\text { MD }\end{array}$ & $\begin{array}{l}\text { University Hospital of } \\
\text { Rennes, France }\end{array}$ & $\begin{array}{l}\text { Acquisition of data; revised } \\
\text { the manuscript for } \\
\text { intellectual content }\end{array}$ \\
\hline $\begin{array}{l}\text { Béatrice } \\
\text { Carsin-Nicol, } \\
\text { MD }\end{array}$ & $\begin{array}{l}\text { University Hospital of } \\
\text { Rennes, France }\end{array}$ & $\begin{array}{l}\text { Acquisition of data; revised } \\
\text { the manuscript for } \\
\text { intellectual content }\end{array}$ \\
\hline $\begin{array}{l}\text { Pierre-Olivier } \\
\text { Comby, MD }\end{array}$ & $\begin{array}{l}\text { University hospitals } \\
\text { of Dijon, France }\end{array}$ & $\begin{array}{l}\text { Acquisition of data; revised } \\
\text { the manuscript for } \\
\text { intellectual content }\end{array}$ \\
\hline $\begin{array}{l}\text { Frédéric } \\
\text { Ricolfi, MD, } \\
\text { PhD }\end{array}$ & $\begin{array}{l}\text { University hospitals } \\
\text { of Dijon, France }\end{array}$ & $\begin{array}{l}\text { Acquisition of data; revised } \\
\text { the manuscript for } \\
\text { intellectual content }\end{array}$ \\
\hline $\begin{array}{l}\text { Pierre } \\
\text { Thouant, MD }\end{array}$ & $\begin{array}{l}\text { University hospitals } \\
\text { of Dijon, France }\end{array}$ & $\begin{array}{l}\text { Acquisition of data; revised } \\
\text { the manuscript for } \\
\text { intellectual content }\end{array}$ \\
\hline $\begin{array}{l}\text { Claire Boutet, } \\
\text { MD, PhD }\end{array}$ & $\begin{array}{l}\text { University hospital of } \\
\text { Saint-Etienne, France }\end{array}$ & $\begin{array}{l}\text { Acquisition of data; revised } \\
\text { the manuscript for } \\
\text { intellectual content }\end{array}$ \\
\hline
\end{tabular}


Appendix (continued)

\begin{tabular}{|c|c|c|}
\hline Name & Location & Contribution \\
\hline $\begin{array}{l}\text { Xavier Fabre, } \\
\text { MD }\end{array}$ & $\begin{array}{l}\text { Hospital of Roanne, } \\
\text { France }\end{array}$ & $\begin{array}{l}\text { Acquisition of data; revised } \\
\text { the manuscript for } \\
\text { intellectual content }\end{array}$ \\
\hline $\begin{array}{l}\text { Géraud } \\
\text { Forestier, MD }\end{array}$ & $\begin{array}{l}\text { Hospital of Antony, } \\
\text { France }\end{array}$ & $\begin{array}{l}\text { Acquisition of data; revised } \\
\text { the manuscript for } \\
\text { intellectual content }\end{array}$ \\
\hline $\begin{array}{l}\text { Isaure de } \\
\text { Beaurepaire, } \\
\text { MD }\end{array}$ & $\begin{array}{l}\text { Hospital of Antony, } \\
\text { France }\end{array}$ & $\begin{array}{l}\text { Acquisition of data; revised } \\
\text { the manuscript for } \\
\text { intellectual content }\end{array}$ \\
\hline $\begin{array}{l}\text { Grégoire } \\
\text { Bornet, MD }\end{array}$ & $\begin{array}{l}\text { Hospital of Antony, } \\
\text { France }\end{array}$ & $\begin{array}{l}\text { Acquisition of data; revised } \\
\text { the manuscript for } \\
\text { intellectual content }\end{array}$ \\
\hline $\begin{array}{l}\text { Hubert Desal, } \\
\text { MD, PhD }\end{array}$ & $\begin{array}{l}\text { University Hospital of } \\
\text { Nantes, France }\end{array}$ & $\begin{array}{l}\text { Acquisition of data; revised } \\
\text { the manuscript for } \\
\text { intellectual content }\end{array}$ \\
\hline $\begin{array}{l}\text { Grégoire } \\
\text { Boulouis, MD }\end{array}$ & $\begin{array}{l}\text { Saint-Anne Hospital, } \\
\text { Paris, France }\end{array}$ & $\begin{array}{l}\text { Acquisition of data; revised } \\
\text { the manuscript for } \\
\text { intellectual content }\end{array}$ \\
\hline $\begin{array}{l}\text { Jérome Berge, } \\
\text { MD }\end{array}$ & $\begin{array}{l}\text { University Hospital of } \\
\text { Bordeaux, France }\end{array}$ & $\begin{array}{l}\text { Acquisition of data; revised } \\
\text { the manuscript for } \\
\text { intellectual content }\end{array}$ \\
\hline $\begin{array}{l}\text { Apolline } \\
\text { Kazémi, MD }\end{array}$ & $\begin{array}{l}\text { University Hospital of } \\
\text { Lille, France }\end{array}$ & $\begin{array}{l}\text { Acquisition of data; revised } \\
\text { the manuscript for } \\
\text { intellectual content }\end{array}$ \\
\hline $\begin{array}{l}\text { Nadya } \\
\text { Pyatigorskaya, } \\
\text { MD }\end{array}$ & $\begin{array}{l}\text { Pitié-Salpêtrière } \\
\text { Hospital, Paris, } \\
\text { France }\end{array}$ & $\begin{array}{l}\text { Acquisition of data; revised } \\
\text { the manuscript for } \\
\text { intellectual content }\end{array}$ \\
\hline $\begin{array}{l}\text { Augustin } \\
\text { Lecler, MD }\end{array}$ & $\begin{array}{l}\text { Foundation A. } \\
\text { Rothschild, Paris }\end{array}$ & $\begin{array}{l}\text { Acquisition of data; revised } \\
\text { the manuscript for } \\
\text { intellectual content }\end{array}$ \\
\hline $\begin{array}{l}\text { Suzana } \\
\text { Saleme, MD }\end{array}$ & $\begin{array}{l}\text { University Hospital of } \\
\text { Limoges, France }\end{array}$ & $\begin{array}{l}\text { Acquisition of data; revised } \\
\text { the manuscript for } \\
\text { intellectual content }\end{array}$ \\
\hline $\begin{array}{l}\text { Myriam Edjlali- } \\
\text { Goujon, MD }\end{array}$ & $\begin{array}{l}\text { Saint-Anne Hospital, } \\
\text { Paris, France }\end{array}$ & $\begin{array}{l}\text { Acquisition of data; revised } \\
\text { the manuscript for } \\
\text { intellectual content }\end{array}$ \\
\hline $\begin{array}{l}\text { Basile } \\
\text { Kerleroux, MD }\end{array}$ & $\begin{array}{l}\text { University Hospital of } \\
\text { Tours, France }\end{array}$ & $\begin{array}{l}\text { Acquisition of data; revised } \\
\text { the manuscript for } \\
\text { intellectual content }\end{array}$ \\
\hline $\begin{array}{l}\text { Jean-Marc } \\
\text { Constans, MD, } \\
\text { PhD }\end{array}$ & $\begin{array}{l}\text { University Hospital of } \\
\text { Amiens, France }\end{array}$ & $\begin{array}{l}\text { Acquisition of data; revised } \\
\text { the manuscript for } \\
\text { intellectual content }\end{array}$ \\
\hline $\begin{array}{l}\text { Pierre- } \\
\text { Emmanuel } \\
\text { Zorn, PhD }\end{array}$ & $\begin{array}{l}\text { University Hospitals } \\
\text { of Strasbourg, France }\end{array}$ & $\begin{array}{l}\text { Major role in the acquisition } \\
\text { of data }\end{array}$ \\
\hline $\begin{array}{l}\text { Muriel } \\
\text { Matthieu, PhD }\end{array}$ & $\begin{array}{l}\text { University Hospitals } \\
\text { of Strasbourg, France }\end{array}$ & $\begin{array}{l}\text { Major role in the acquisition } \\
\text { of data }\end{array}$ \\
\hline $\begin{array}{l}\text { Seyyid Baloglu, } \\
\text { MD }\end{array}$ & $\begin{array}{l}\text { University Hospitals } \\
\text { of Strasbourg, France }\end{array}$ & $\begin{array}{l}\text { Acquisition of data; } \\
\text { revised the manuscript } \\
\text { for intellectual } \\
\text { content }\end{array}$ \\
\hline $\begin{array}{l}\text { François- } \\
\text { Daniel } \\
\text { Ardellier, MD }\end{array}$ & $\begin{array}{l}\text { University Hospitals } \\
\text { of Strasbourg, France }\end{array}$ & $\begin{array}{l}\text { Acquisition of data; revised } \\
\text { the manuscript for } \\
\text { intellectual content }\end{array}$ \\
\hline $\begin{array}{l}\text { Thibault } \\
\text { Willaume, MD }\end{array}$ & $\begin{array}{l}\text { University Hospitals } \\
\text { of Strasbourg, France }\end{array}$ & $\begin{array}{l}\text { Acquisition of data; } \\
\text { revised the manuscript } \\
\text { for intellectual } \\
\text { content }\end{array}$ \\
\hline
\end{tabular}

Appendix (continued)

\begin{tabular}{|c|c|c|}
\hline Name & Location & Contribution \\
\hline $\begin{array}{l}\text { Jean- } \\
\text { Christophe } \\
\text { Brisset, PhD }\end{array}$ & $\begin{array}{l}\text { French Observatory } \\
\text { of Multiple Sclerosis, } \\
\text { Lyon, France }\end{array}$ & $\begin{array}{l}\text { Interpretation of the data; } \\
\text { revised the manuscript for } \\
\text { intellectual content }\end{array}$ \\
\hline $\begin{array}{l}\text { Sophie } \\
\text { Caillard, MD, } \\
\text { PhD }\end{array}$ & $\begin{array}{l}\text { University Hospitals } \\
\text { of Strasbourg, France }\end{array}$ & $\begin{array}{l}\text { Acquisition of data; revised } \\
\text { the manuscript for } \\
\text { intellectual content }\end{array}$ \\
\hline $\begin{array}{l}\text { Olivier } \\
\text { Collange, MD, } \\
\text { PhD }\end{array}$ & $\begin{array}{l}\text { University Hospitals } \\
\text { of Strasbourg, France }\end{array}$ & $\begin{array}{l}\text { Acquisition of data; revised } \\
\text { the manuscript for } \\
\text { intellectual content }\end{array}$ \\
\hline $\begin{array}{l}\text { Paul Michel } \\
\text { Mertes, MD, } \\
\text { PhD }\end{array}$ & $\begin{array}{l}\text { University Hospitals } \\
\text { of Strasbourg, France }\end{array}$ & $\begin{array}{l}\text { Acquisition of data; revised } \\
\text { the manuscript for } \\
\text { intellectual content }\end{array}$ \\
\hline $\begin{array}{l}\text { Francis } \\
\text { Schneider, MD, } \\
\text { PhD }\end{array}$ & $\begin{array}{l}\text { University Hospitals } \\
\text { of Strasbourg, France }\end{array}$ & $\begin{array}{l}\text { Acquisition of data; revised } \\
\text { the manuscript for } \\
\text { intellectual content }\end{array}$ \\
\hline $\begin{array}{l}\text { Samira Fafi- } \\
\text { Kremer, } \\
\text { PharmD }\end{array}$ & $\begin{array}{l}\text { University Hospitals } \\
\text { of Strasbourg, France }\end{array}$ & $\begin{array}{l}\text { Acquisition of data; revised } \\
\text { the manuscript for } \\
\text { intellectual content }\end{array}$ \\
\hline $\begin{array}{l}\text { Mickael } \\
\text { Ohana, MD, } \\
\text { PhD }\end{array}$ & $\begin{array}{l}\text { University Hospitals } \\
\text { of Strasbourg, France }\end{array}$ & $\begin{array}{l}\text { Acquisition of data; revised } \\
\text { the manuscript for } \\
\text { intellectual content }\end{array}$ \\
\hline $\begin{array}{l}\text { Ferhat } \\
\text { Meziani, MD, } \\
\text { PhD }\end{array}$ & $\begin{array}{l}\text { University Hospitals } \\
\text { of Strasbourg, France }\end{array}$ & $\begin{array}{l}\text { Acquisition of data; revised } \\
\text { the manuscript for } \\
\text { intellectual content }\end{array}$ \\
\hline $\begin{array}{l}\text { Nicolas Meyer, } \\
\text { MD, PhD }\end{array}$ & $\begin{array}{l}\text { University Hospitals } \\
\text { of Strasbourg, France }\end{array}$ & $\begin{array}{l}\text { Major role in the analysis and } \\
\text { interpretation of the data }\end{array}$ \\
\hline $\begin{array}{l}\text { Julie Helms, } \\
\text { MD, PhD }\end{array}$ & $\begin{array}{l}\text { University Hospitals } \\
\text { of Strasbourg, France }\end{array}$ & $\begin{array}{l}\text { Designed and conceptualized } \\
\text { the study; interpreted the } \\
\text { data; revised the manuscript } \\
\text { for intellectual content }\end{array}$ \\
\hline $\begin{array}{l}\text { François } \\
\text { Cotton, MD, } \\
\text { PhD }\end{array}$ & $\begin{array}{l}\text { University Hospitals } \\
\text { of Strasbourg, France }\end{array}$ & $\begin{array}{l}\text { Designed and conceptualized } \\
\text { the study; interpreted the } \\
\text { data; revised the manuscript } \\
\text { for intellectual content }\end{array}$ \\
\hline
\end{tabular}

\section{References}

1. Chen N, Zhou M, Dong X, et al. Epidemiological and clinical characteristics of 99 cases of 2019 novel coronavirus pneumonia in Wuhan, China: a descriptive study. Lancet 2020;395:507-513.

2. Huang C, Wang Y, Li X, et al. Clinical features of patients infected with 2019 novel coronavirus in Wuhan, China. Lancet 2020;395:497-506.

3. Glass WG, Subbarao K, Murphy B, Murphy PM. Mechanisms of host defense following severe acute respiratory syndrome-coronavirus (SARS-CoV) pulmonary infection of mice. J Immunol 2004;173:4030-4039.

4. Li K, Wohlford-Lenane C, Perlman S, et al. Middle East respiratory syndrome coronavirus causes multiple organ damage and lethal disease in mice transgenic for human dipeptidyl peptidase 4. J Infect Dis 2016;213:712-722.

5. Arbour N, Day R, Newcombe J, Talbot PJ. Neuroinvasion by human respiratory coronaviruses. J Virol 2000;74:8913-8921.

6. Desforges M, Le Coupanec A, Stodola JK, Meessen-Pinard M, Talbot PJ. Human coronaviruses: viral and cellular factors involved in neuroinvasiveness and neuropathogenesis. Virus Res 2014;194:145-158.

7. Desforges M, Le Coupanec A, Dubeau P, et al. Human coronaviruses and other respiratory viruses: underestimated opportunistic pathogens of the central nervous system? Viruses 2019;12:E14.

8. Bohmwald K, Gálvez NMS, Ríos M, Kalergis AM. Neurologic alterations due to respiratory virus infections. Front Cell Neurosci 2018;12:386.

9. Poyiadji N, Shahin G, Noujaim D, Stone M, Patel S, Griffith B. COVID-19-associated acute hemorrhagic necrotizing encephalopathy: CT and MRI features. Radiology 2020:201187.

10. Moriguchi T, Harii N, Goto J, et al. A first case of meningitis/encephalitis associated with SARS-coronavirus-2. Int J Infect Dis 2020;94:55-58.

11. Mao L, Jin H, Wang M, et al. Neurologic manifestations of hospitalized patients with coronavirus disease 2019 in Wuhan, China. JAMA Neurol 2020;77:1-9. 
12. Helms J, Kremer S, Merdji H, et al. Neurologic features in severe SARS-CoV-2 infection. N Engl J Med 2020;382:2268-2270.

13. Kandemirli SG, Dogan L, Sarikaya ZT, et al. Brain MRI findings in patients in the intensive care unit with COVID-19 infection. Radiology Epub 2020 May 8.

14. Ferguson ND, Fan E, Camporota L, et al. The Berlin definition of ARDS: an expanded rationale, justification, and supplementary material. Intensive Care Med 2012;38: 1573-1582.

15. Starkey J, Kobayashi N, Numaguchi Y, Moritani T. Cytotoxic lesions of the corpus callosum that show restricted diffusion: mechanisms, causes, and manifestations. Radiographics 2017;37:562-576.

16. Beyrouti R, Adams ME, Benjamin L, et al. Characteristics of ischaemic stroke associated with COVID-19. J Neurol Neurosurg Psychiatry Epub 2020 Apr 30.

17. Hess DC, Eldahshan W, Rutkowski E. COVID-19-related stroke. Transl Stroke Res 2020;11:322-325.

18. Umapathi $\mathrm{T}$, Kor $\mathrm{AC}$, Venketasubramanian $\mathrm{N}$, et al. Large artery ischaemic stroke in severe acute respiratory syndrome (SARS). J Neurol 2004;251:1227-1231.

19. Arabi YM, Harthi A, Hussein J, et al. Severe neurologic syndrome associated with Middle East respiratory syndrome corona virus (MERS-CoV). Infection 2015;43: 495-501.

20. Guo T, Fan Y, Chen M, et al. Cardiovascular implications of fatal outcomes of patients with coronavirus disease 2019 (COVID-19). JAMA Cardiol Epub 2020 Mar 27.

21. Helms J, Tacquard C, Severac F, et al. High risk of thrombosis in patients in severe SARS-CoV-2 infection: a multicenter prospective cohort study. Intensive Care Med 2020;46:1089-1098.

22. Nagel MA, Mahalingam R, Cohrs RJ, Gilden D. Virus vasculopathy and stroke: an underrecognized cause and treatment target. Infect Disord Drug Targets 2010;10:105-111.

23. Subramaniam S, Scharrer I. Procoagulant activity during viral infections. Front Biosci (Landmark Ed) 2018;23:1060-1081.
24. Hung EC, Chim SS, Chan PK, et al. Detection of SARS coronavirus RNA in the cerebrospinal fluid of a patient with severe acute respiratory syndrome. Clin Chem 2003;49:2108-2109.

25. Lau KK, Yu WC, Chu CM, Lau ST, Sheng B, Yuen KY. Possible central nervous system infection by SARS coronavirus. Emerg Infect Dis 2004;10:342-344.

26. Toledano M, Davies NWS. Infectious encephalitis: mimics and chameleons. Pract Neurol 2019;19:225-237.

27. Kim JE, Heo JH, Kim HO, et al. Neurological complications during treatment of Middle East respiratory syndrome. J Clin Neurol 2017;13:227-233.

28. Li Y, Li H, Fan R, et al. Coronavirus infections in the central nervous system and respiratory tract show distinct features in hospitalized children. Intervirology 2016;59: 163-169.

29. Yeh EA, Collins A, Cohen ME, Duffner PK, Faden H. Detection of coronavirus in the central nervous system of a child with acute disseminated encephalomyelitis. Pediatrics 2004;113(pt 1):e73-e76.

30. Kivisäkk P, Imitola J, Rasmussen S, et al. Localizing central nervous system immune surveillance: meningeal antigen-presenting cells activate $\mathrm{T}$ cells during experimental autoimmune encephalomyelitis. Ann Neurol 2009;65:457-469.

31. Absinta M, Cortese IC, Vuolo L, et al. Leptomeningeal gadolinium enhancement across the spectrum of chronic neuroinflammatory diseases. Neurology 2017;88: 1439-1444.

32. Papatsiros VG, Stylianaki I, Papakonstantinou G, Papaioannou N, Christodoulopoulos G. Case report of transmissible gastroenteritis coronavirus infection associated with small intestine and brain lesions in piglets. Viral Immunol 2019;32:63-67.

33. Stuckey SL, Goh TD, Heffernan T, Rowan D. Hyperintensity in the subarachnoid space on FLAIR MRI. AJR Am J Roentgenol 2007;189:913-921.

34. Parpia AS, Li Y, Chen C, Dhar B, Crowcroft NS. Encephalitis, Ontario, Canada, 2002 2013. Emerg Infect Dis 2016;22:426-432. 


\section{Neurology}

\section{Neurologic and neuroimaging findings in patients with COVID-19: A retrospective multicenter study}

Stéphane Kremer, François Lersy, Mathieu Anheim, et al.

Neurology 2020;95; 1868-e1882 Published Online before print July 17, 2020

DOI 10.1212/WNL.0000000000010112

This information is current as of July 17, 2020

Updated Information \&
Services

References

Citations

Subspecialty Collections

Permissions \& Licensing

Reprints including high resolution figures, can be found at: http://n.neurology.org/content/95/13/e1868.full

This article cites 30 articles, 5 of which you can access for free at: http://n.neurology.org/content/95/13/e1868.full\#ref-list-1

This article has been cited by 7 HighWire-hosted articles: http://n.neurology.org/content/95/13/e1868.full\#\#otherarticles

This article, along with others on similar topics, appears in the following collection(s):

All Cerebrovascular disease/Stroke

http://n.neurology.org/cgi/collection/all_cerebrovascular_disease_strok e

Encephalitis

http://n.neurology.org/cgi/collection/encephalitis

Meningitis

http://n.neurology.org/cgi/collection/meningitis

MRI

http://n.neurology.org/cgi/collection/mri

Information about reproducing this article in parts (figures,tables) or in its entirety can be found online at:

http://www.neurology.org/about/about_the_journal\#permissions

Information about ordering reprints can be found online:

http://n.neurology.org/subscribers/advertise

Neurology ${ }^{\circledR}$ is the official journal of the American Academy of Neurology. Published continuously since 1951, it is now a weekly with 48 issues per year. Copyright (C 2020 American Academy of Neurology. All rights reserved. Print ISSN: 0028-3878. Online ISSN: 1526-632X.

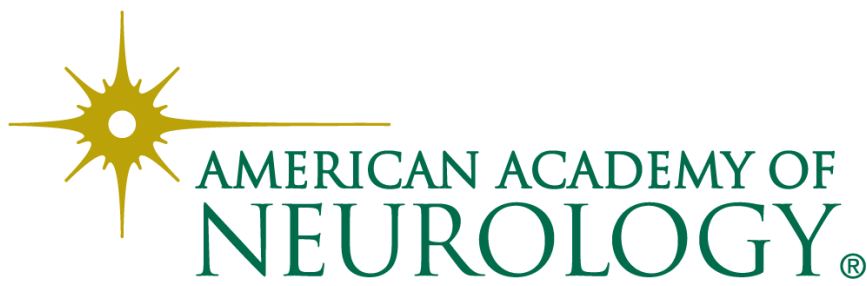

